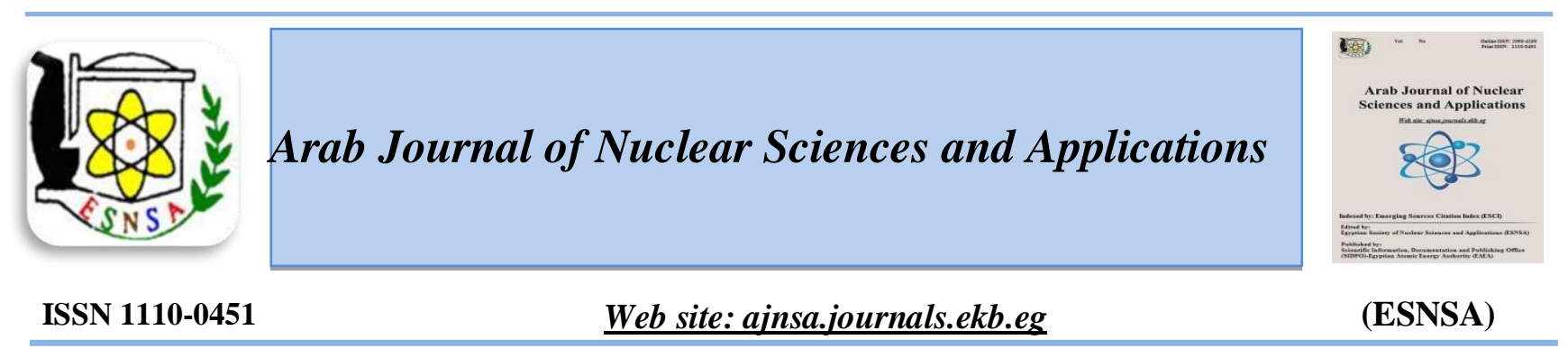

\title{
Influence of Some Electrodeposition Parameters on Formation of Nanostructure Black Cobalt Coating used for Solar Energy Absorption
}

\author{
A. M. Raslan ${ }^{(1)}$, M. Nabiel ${ }^{(1)}$, A. F. Waheed ${ }^{(2)}$, Randa A. Kerem $^{(1)}$ \\ ${ }^{(1)}$ Metallurgy Department, Faculty of Engineering, Cairo University, Giza, Egypt \\ ${ }^{(2)}$ Materials Division, Metallurgy Department, Nuclear Research Center, Atomic Energy Authority, Cairo, Egypt
}

Received $2^{\text {th }}$ Nov. 2018 Electrodeposition of nano cobalt on a stainless steel 304 substrate used for solar energy absorption was Accepted $8^{\text {th }}$ May 2019 established. Two different electrolytic bathes were used in this investigation. The first bath composition was $\left[270 \mathrm{~g} / \mathrm{l} \mathrm{CoSO}, 35 \mathrm{~g} / \mathrm{l} \mathrm{CoCl}_{2}, 2.5 \mathrm{~g} / \mathrm{l} \mathrm{Co}\left(\mathrm{NO}_{3}\right)_{2}\right.$ and $\left.30 \mathrm{~g} / \mathrm{H}_{3} \mathrm{BO}_{3}\right]$, and the second was as the previous without addition of $\mathrm{Co}\left(\mathrm{NO}_{3}\right)_{2}$. The role of nitrate ions as an oxidizing agent was investigated. Different current densities $\left(20\right.$ and $\left.30 \mathrm{~mA} / \mathrm{cm}^{2}\right)$ were applied. The optimum time of deposition was found to be 6 minutes for each used current density. Crystal structure transformation and morphology changes were investigated for coatings at all electrodeposition conditions. SEM and EDAX were used for monitoring the gradual changes in the coated surface and nanostructure formation behavior. The degree of crystallinity and crystallite size changes were measured using XRD. The optical properties such as absorption and reflectivity were investigated using UV-IR Spectrometry to find and compromise the effect of applied electrodeposition conditions on the solar energy absorption of the formed surface coating. The absorptance had values up to $\mathbf{9 8 \%}$ for the high energy region of sunlight spectrum at electrodeposition conditions of the first bath when using cobalt nitrate.

Keywords: lack, cobalt coating, current density, electrodeposition bath, nanostructure.

\section{Introduction}

The solar energy technologies are mainly composed of solar cell and solar collector technologies. A solar cell is used for converting solar radiation to electricity, and a solar collector converts radiation into heat. The conversion of solar radiation to heat is considered as a very efficient way to provide space heating, domestic hot water, industrial process heating, desalinated sea water or generation of solar electricity. The thermal efficiency of a solar collector can be improved by using an absorber plate coated with a solar selective coating. [1] The optically selective coating on the solar absorber should ideally behave as a black body, absorbing a maximum of the incoming solar radiation while minimizing energy losses by infrared radiation, acting as an infrared mirror. Therefore, a selective surface should have the lowest possible spectral reflectivity in the spectral range of solar radiation and the highest possible one in the range of infrared emission at the given temperature of the absorber.[2]

Electrodeposition becomes particularly attractive when the immobilization of nanostructures onto conductive substrates is required. Compared to solution phase methods, electrodeposition can enhance the controllability of nanostructure morphology. Morphologies spanning from compact faceted nano-crystals to dendritic and fractal nanostructures [3] can be generated by varying the electrode potential and/or the concentration of the precursor metal ion. Spherical, worm and grain like cobalt oxide nano-particles [4, 5] were electrodeposited onto glassy carbon electrode by cyclic voltammetry while a network of nano-layered cobalt hydroxide sheets were obtained by potentiostatic electrodeposition from cobalt nitrate solution. Cobalt nanostructures with

Corresponding author: ahraslan@gmail.com

DOI: 10.21608/ajnsa.2019.6188.1143

(C) Scientific Information, Documentation and Publishing Office (SIDPO)-EAEA 
tree-like morphology [6] were synthesized by potentiostatic electrodeposition onto a selfassembled gold nanoparticle modified glassy carbon electrode. Isolated aggregates of cobalt nanoparticles were generated by pulsed current electrodeposition [7]. Recently, attention has been devoted to the electrochemical synthesis of cobalt hydroxide nano flaks [8]. There are nano porous structures composed of interconnected sheets with thickness and crystallite size around $10 \mathrm{~nm}$ [9].

Because of its optical, semiconducting, magnetic, and electrochemical properties, black cobalt (cobalt oxide) is a promising material among transition metal oxides, which render it attractive for solar photochemical applications and electrochemical devices as a counter electrode. [3] Cobalt oxide compounds are conventionally obtained by the thermal method and also by electrochemical deposition from electrolytes based on cobalt sulfate [10], acetate [11], chloride [12], or nitrate [13]. At the same time, with electrolytes containing fluoride ions as ligands, the technology for obtaining oxide compounds of a number of transition metals can be substantially simplified through use, under these conditions, of a dual functional electrochemical system electrode/film/electrolyte, whose central phase contains lower content of high charged forms of a metal. At the electrolyte/film interface, the film itself is formed through electrolytic reduction of ions of the discharging metal (or electrolytic oxidation of the metal) to an intermediate oxidation state and dissolution of the film in the electrolyte. At the electrode/film interface, the film substance is consumed for its further reduction to metal or its oxidation to the higher oxidation state. As a result of these simultaneous processes, the film is permanently in the state of dynamic equilibrium. As a rule, such oxide compounds have reproducible composition; depending on the process conditions, they can be obtained either as compact film coatings, usually black, or as powders. [14]

In this study the influence of some electrodeposition parameters, like deposition time, current density, and addition of cobalt nitrate as an oxidizing agent to the electrolyte solution, will be investigated. Synthesis of cobalt oxide nanostructure by annealing thermal treatment, and the morphology changes of the formed layers will be studied. Then, the effect of all these variables on the surface topography, roughness and solar absorption behavior will be investigated.

\section{Experimental Work \\ Substrate Preparation}

The substrates were stainless steel 304 plates of 9 $\mathrm{cm}^{2}$ surface area. The sample was embedded in an epoxy resin in such a way that only one face was exposed to the solution. Direct cleaning of the surface using acetone, followed by ultrasonic cleaning for 5 minutes with immersion in ethanol was performed. Activation of cleaned surface was done by immersing it in (10\%) diluted $\mathrm{HCl}$ solution for 2 minutes, then washing with double distilled water (DDW).

\section{Electrodeposition Process}

An oxidizing agent, cobalt nitrate $\left[\mathrm{Co}\left(\mathrm{NO}_{3}\right)_{2}\right]$ was added to electrolyte composition named Bath- 1 as presented in table (1). The same previous composition was used without adding cobalt nitrate to form Bath- 2 . All solutions were prepared from ultrapure analytical grade reagents, and double distilled water. Experiments were carried out at room temperature in a conventional three-electrode cell. Stainless steel (type 304) sheet with a $9.0 \mathrm{~cm}^{2}$ surface area was used as the working electrode. A platinum sheet with $8.0 \mathrm{~cm}^{2}$ surface area was utilized as the counter electrode and a saturated calomel electrode (SCE) as the reference electrode. The electrodeposition experimental parameters are summarized in table (2).

Table (1): Chemical composition of the aqueous electrolytic baths

\begin{tabular}{lll}
\hline \multirow{2}{*}{ Chemical } & Concentration $($ gm / liter ) \\
\cline { 2 - 3 } Compound & Bath-1 & Bath-2 \\
\hline Cobalt Sulfate $\left[\mathrm{CoSO}_{4}-7 \mathrm{H}_{2} \mathrm{O}\right]$ & 270 & 270 \\
Cobalt Chloride $\left[\mathrm{CoCl}_{2}-6 \mathrm{H}_{2} \mathrm{O}\right]$ & 35 & 35 \\
Cobalt Nitrate $\left[\mathrm{Co}\left(\mathrm{No}_{3}\right)_{2}-6 \mathrm{H}_{2} \mathrm{O}\right]$ & 2.5 & 0.0 \\
Boric Acid $\left[\mathrm{H}_{3} \mathrm{Bo}_{3}\right]$ & 30 & 30 \\
\hline
\end{tabular}

Table (2): Electrodeposition process working parameters Parameter Value 


\begin{tabular}{cc}
\hline $\mathrm{pH}$ & 3.5 \\
Current Density & 20, and 30 \\
{$\left[\mathrm{~mA} / \mathrm{cm}^{2}\right]$} & Room Temp. \\
Temperature $\left[{ }^{0} \mathrm{C}\right]$ & 1 to 9 \\
Deposition Time $[\mathrm{min}]$. & \\
\hline
\end{tabular}

\section{Thermal Treatment}

The deposited pure cobalt films recently obtained were subjected to annealing heat treatment. The thermal treatment consists of the positioning of several samples in a furnace at $400^{\circ} \mathrm{C}$ for $10 \mathrm{~h}$ holding time interval, followed by furnace cooling.

\section{Metallic Cobalt and cobalt oxide films} characterization

Surface characterization of the cobalt metal and oxide coating was obtained by X-ray diffraction (XRD) using Panalytical X'Pert PRO Materials Research Diffractometer, Holland. The crystallite size $\mathbf{D}_{\text {hkl }}$ was calculated from the line broadening using the Scherer's equation: [11]

$$
D_{h k l}=\frac{k \cdot \lambda}{B_{h k l} \cdot \cos \theta}
$$

Where; $\lambda$ is the wavelength of the $\mathrm{CuK}_{\alpha}$ radiation $\left(1.54056 \times 10^{-10} \mathrm{~m}\right), \boldsymbol{\theta}$ the Bragg diffraction angle, $\boldsymbol{B}_{\boldsymbol{h k l}}$ the full width at the half maximum intensity of the characteristic reflection peak $\left(2 \boldsymbol{\theta}=36.86^{\circ}\right)$, and $\boldsymbol{k}$ a constant (Usually $\boldsymbol{k}=0.94$ ).

To observe the overall properties of the cobalt and cobalt oxide films, a scanning electron microscope (SEM) Model Quanta 250 FEG (Field Emission Gun) attached with EDX Unit (Energy Dispersive $\mathrm{X}$-ray Analyses), with accelerating voltage 30 K.V., magnification $14 x$ up to 1000000 and resolution for Gun.1n). FEI Company, Netherlands was used. The Surface Topography was measured by using 3D Image Analyzing Software [SCANDIUM Software].

Mitutoyo surface roughness measuring system, model SURFTEST.301, Japan, was used for surface layer roughness measurements. UVvisible-near IR spectrophotometer (JASCO-V-570) was used in measuring the optical properties of cobalt metal and its oxide layers, Japan (integrating sphere reflectance unit).

\section{Results And Discussion}

Effect of electrodeposition parameters
Electrodeposition times from 1 min. to 9 min. were used, which means nine experiments for each applied current density (20, and $\left.30 \mathrm{~mA} / \mathrm{cm}^{2}\right)$. According to the XRD and SEM results for each experiment, the optimum holding time was found to be $6 \mathrm{~min}$. At times less than 6 minutes uncompleted coverage of deposited layer was observed especially at lower current density (20 $\mathrm{mA} / \mathrm{cm} 2$ ). Based on the naked eye observation, for times above 6 minutes peel off at the edges of the substrate was observed especially at higher current density $\left(30 \mathrm{~mA} / \mathrm{cm}^{2}\right)$, because of brittle properties of deposit and the built-in high internal stress in the coating layer [3]. Therefore, in this study 6 minutes was chosen as an optimum deposition time and as fixed factor for a comparison purpose. Also, during the scope of this work the $\mathrm{pH}$ was fixed at 3.5 for all electrodeposition experiments due to the presence of acidic salts used in the electrolytic bath as mentioned in table (1). Boric acid is a common additive found in nearly all aqueous transition metal plating solutions, for its influence on metal nanostructure deposition. [15]

For bath-1, using cobalt nitrate as an oxidizing agent, an intermediate oxidation state and dissolution of the formed cobalt film in the electrolyte take place followed by reformation of pure cobalt deposit again according to the faradaic reactions (1, 3and 4) and chemical reaction no. (2).

$$
\mathrm{Co}_{(\mathrm{aq})}{ }^{+2}(M .)+2 \mathrm{e}^{-1} \leftrightarrow \mathrm{Co}_{(\mathrm{ss})}
$$

$$
\begin{aligned}
& 2 \mathrm{H}_{(\mathrm{aq})}{ }^{+1}+\mathrm{NO}_{3(\mathrm{aq})}^{-1}+\mathrm{Co}_{(\mathrm{ss})} \\
& \mathrm{NO}_{2(\mathrm{aq})}{ }^{-1}+\mathrm{H}_{2} \mathrm{O}
\end{aligned} \text { Co } \mathrm{Co}_{(\mathrm{aq})}^{+2}(\mathrm{OX} .)+
$$

Considering reaction [2], we propose simultaneous nitrate reduction during the cathodic process according to the following reaction;

$$
\begin{aligned}
& 2 \mathrm{H}_{(\mathrm{aq})}{ }^{+1}+\mathrm{NO}_{3(\mathrm{aq})}{ }^{-1}+2 \mathrm{e}^{-1}(\mathrm{Co}) \leftrightarrow \mathrm{NO}_{2(\mathrm{aq})}{ }^{-1}+ \\
& \mathbf{H}_{2} \mathbf{O}_{(\mathbf{l})}
\end{aligned}
$$

And also a reduction to the oxidized cobalt ions during the cathodic process according to the following reaction;

$$
\mathrm{Co}_{(\mathrm{aq})}{ }^{+2}(O X .)+2 \mathrm{e}^{-1} \leftrightarrow \mathrm{Co}_{(\mathrm{ss})}
$$


On the other hand, in Bath-2 the main cathodic reaction is the reduction of cobalt ions to form pure cobalt deposits according to the faradic reaction (1).

As shown from figure (1), the efficiency value of the electrodeposition process in case of using bath2 was high, due to normal consumption of the electrons through the anodic and cathodic reactions. While, in case of using bath-1, the efficiency value was low due to the intermediate oxidation reactions, and high consumption of the electrons into the cathodic reactions caused by the addition of cobalt nitrate.

The further increase in the current density affects the solution in the vicinity of the cathode tending to increase the depletion of metallic ions. Hence, the coating layer on the cathode surface is more compact. This behavior results also an increase in the weight gain and thickness of the deposited cobalt film. Figure (2) shows, the variation of weight gain coefficient versus deposition time at

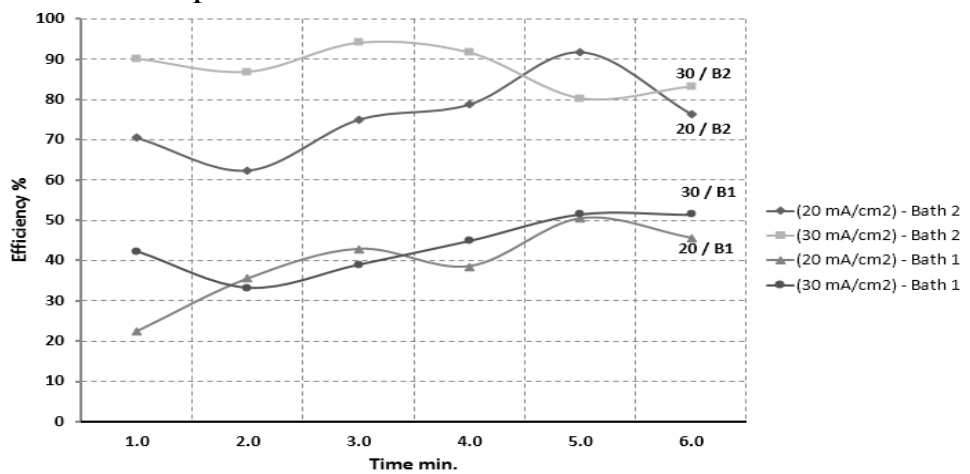

Figure (1): Influence of cobalt nitrate addition on the efficiency of the electrodeposition process at the same deposition time for the two current densities.

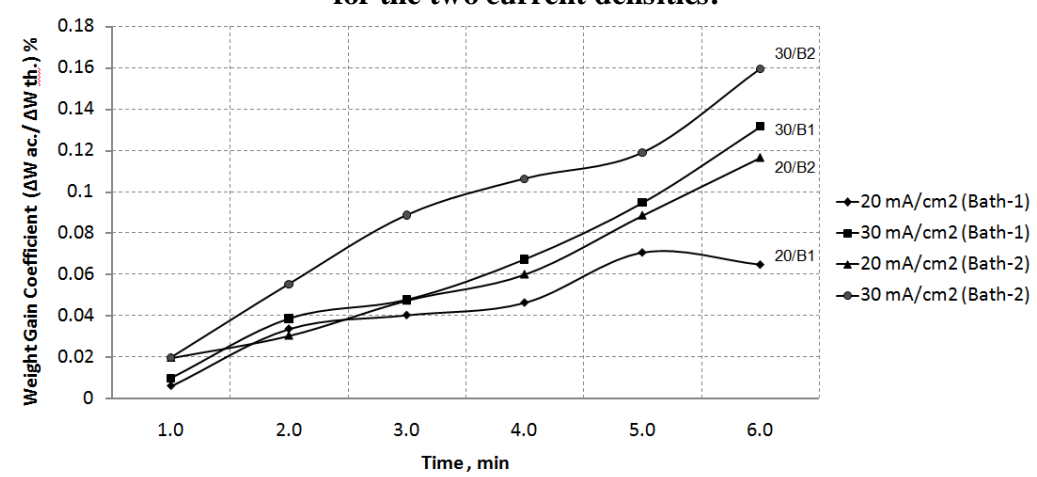

Figure (2): Influence of cobalt nitrate addition on the weight gain from the electrodeposition process at the same deposition time for the two current densities. 
As shown figures (3-a) and (4-a) an obvious change in the preferred orientation of growth was observed. Where, for the deposited cobalt at current density value $\left(20 \mathrm{~mA} / \mathrm{cm}^{2}\right)$ the maximum peak intensity observed was with miller indices (002) which is considered the preferred growth orientation developed into this crystallographic direction at this condition. And, for test condition using current density value $\left(30 \mathrm{~mA} / \mathrm{cm}^{2}\right)$ the maximum peak intensity observed was with miller indices (100) which is considered the preferred growth orientation developed into this crystallographic direction at this condition. But for both conditions, crystal structure was HCP which is characteristics of pure cobalt as described in table (3). Therefore, the behavior and direction of growth of the deposited pure cobalt crystal structure changed with increasing the current density. Also, the crystallite size slightly decreased with the increase of the current density value, as shown in table (4).

Figures (3-b) and (4-b) show the XRD patterns for the cobalt oxides after annealing electrodeposited layers at current densities $\left(20\right.$ and $\left.30 \mathrm{~mA} / \mathrm{cm}^{2}\right)$ respectively. The maximum intensity peak detected was with miller indices (311), which is characteristic for FCC cobalt oxide $\left[\mathrm{Co}_{3} \mathrm{O}_{4}\right]$ crystal structure as given in table (3). Very small peaks corresponding to $[\mathrm{CoO}]$ were detected which indicates the good performance of the oxidation process. The current density had no effect on the direction of growth of the cobalt oxide crystal structure. While, the crystallite size had slightly increased with the increase of the current density,

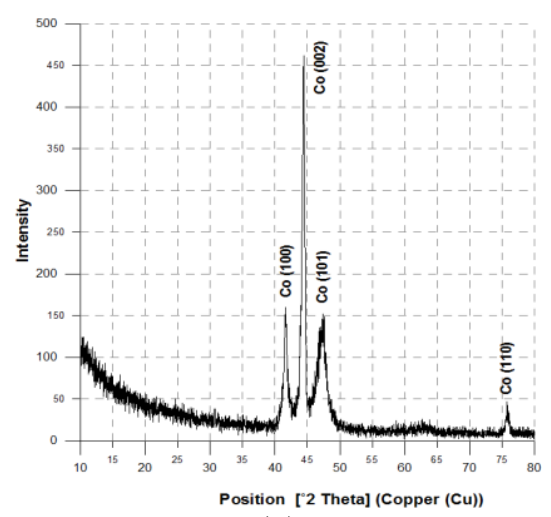

(a) as shown in table (4). It is worth mentioning that, the annealing heat treatment had a clear effect on the crystallite size, which decreased after heat treatment due to crystal structure transformation.

Figures (5) and (6) present the X-ray diffraction patterns of the surface layers electrodeposited in bath- 2 conditions. Pure cobalt in pattern (a), and cobalt oxides formed after annealing heat treatment in pattern (b). The $\mathrm{x}$-ray diffraction patterns of the two studied conditions, have high level of peak intensity and decreasing in the peak broadening compared with bath-1 at the same condition, which give an indication of increase in the degree of crystallinity.

Figures (5-a), and (6-a) show the XRD patterns for the as deposited pure cobalt at electrodeposition current densities (20, and $\left.30 \mathrm{~mA} / \mathrm{cm}^{2}\right)$ respectively. The maximum peak intensity was observed with miller indices (100), which is considered the preferred growth orientation developed into this crystallographic direction for this condition. The structure and direction of growth of the deposited cobalt did not show significant changes with increasing current density. On the other hand, the crystallite size showed a significant increase with the increase of the current density, as shown in table (4). Obviously, there is an evidence of incompactness due to the appearance of peaks related to the austenite substrate.

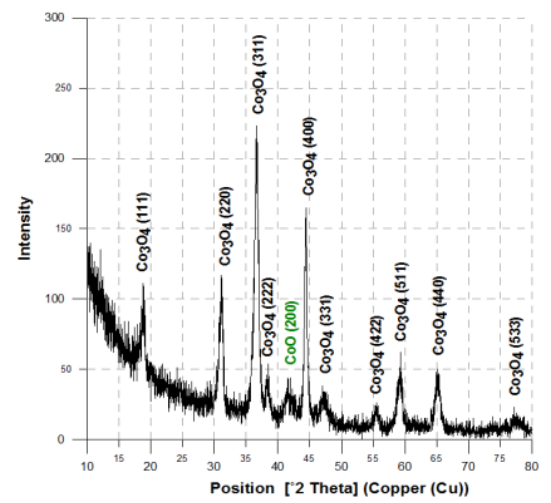

(b)

Figure (3): XRD of stainless steel surface covered with; (a) cobalt metal as deposited, (b) cobalt oxides after annealing $\left(400^{\circ} \mathrm{C} / 10 \mathrm{~h}\right)$. Electrodeposition conditions; current density $\left(20 \mathrm{~mA} / \mathrm{cm}^{2}\right)$, deposition time ( 6 min.) and bath-1 composition 


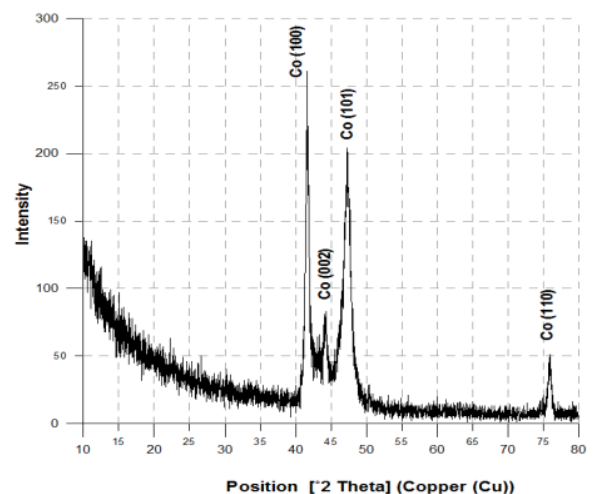

(a)

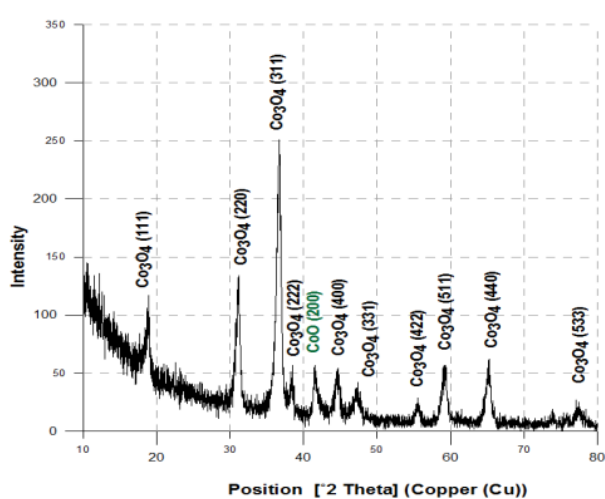

(b)

Figure (4): XRD of stainless steel surface covered with; (a) cobalt metal as deposited, (b) cobalt oxides after annealing $\left(400^{\circ} \mathrm{C} / 10 \mathrm{~h}\right)$. Electrodeposition conditions; current density $\left(30 \mathrm{~mA} / \mathrm{cm}^{2}\right)$, deposition time (6 min) and bath-1 composition

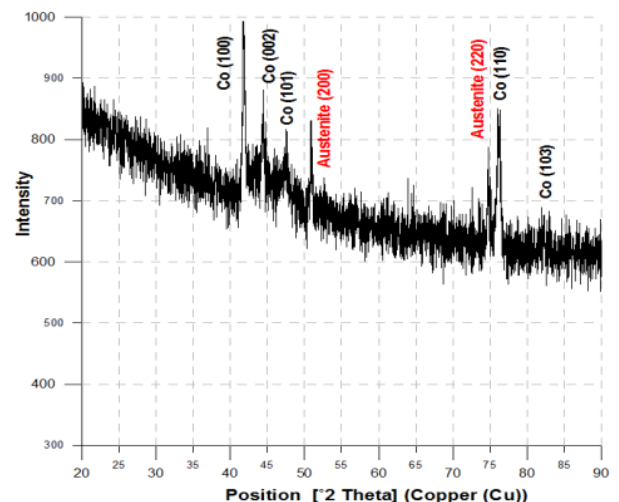

(a)

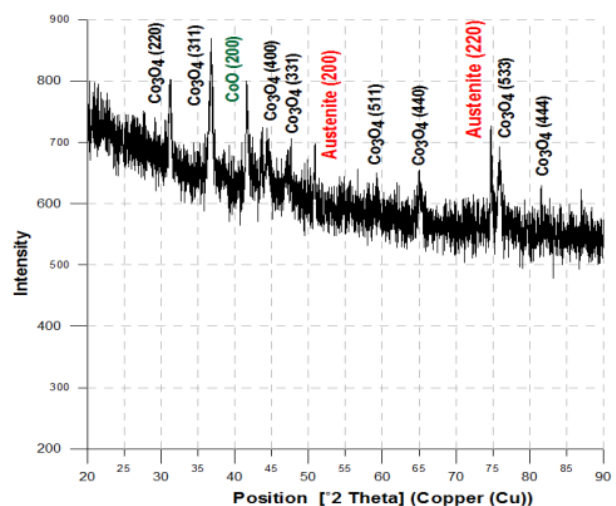

(b)

Figure (5): XRD of stainless steel surface covered with; (a) cobalt metal as deposited, (b) cobalt oxides after annealing $\left(400^{\circ} \mathrm{C} / 10 \mathrm{~h}\right)$. Electrodeposition conditions; current density $\left(20 \mathrm{~mA} / \mathrm{cm}^{2}\right)$, deposition time (6 min) and bath-2 composition

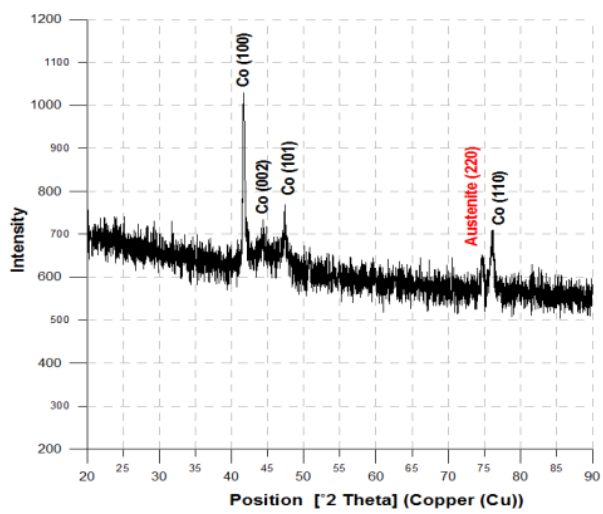

(a)

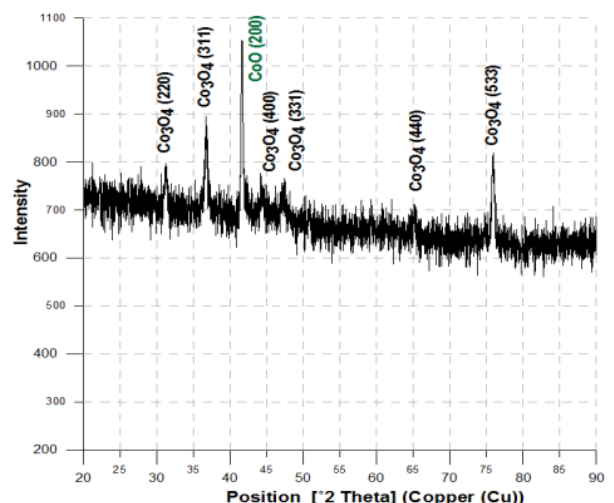

(b)

Figure (6): XRD of stainless steel surface covered with; (a) cobalt metal as deposited, (b) cobalt oxides after annealing $\left(400^{\circ} \mathrm{C} / 10 \mathrm{~h}\right)$. Electrodeposition conditions; current density $\left(30 \mathrm{~mA} / \mathrm{cm}^{2}\right)$, deposition time (6 min) and bath-2 composition. 
Figures (5-b) and (6-b) show the XRD patterns for the cobalt oxides after annealing treatment of the electrodeposited cobalt at current densities (20 and $30 \mathrm{~mA} / \mathrm{cm}^{2}$ ) respectively. Two types of cobalt oxide $\left[\mathrm{Co}_{3} \mathrm{O}_{4}\right.$ and $\left.\mathrm{CoO}\right]$ peaks appear in the XRD patterns, which gives an indication of uncompleted oxidation process. Characteristics of FCC cobalt oxide crystal structure system are given in table (3). For cobalt oxide type $\left[\mathrm{Co}_{3} \mathrm{O}_{4}\right]$ the maximum peak intensity was with miller indices (311), which is considered the preferred growth orientation developed in this crystallographic direction for this condition. And, the maximum peak intensity with miller indices (200) was observed for cobalt oxide type $[\mathrm{CoO}]$, which is considered the preferred growth orientation developed in this crystallographic direction for this condition.

Therefore, the behavior and direction of growth of the cobalt oxides crystal structure had a significant change with increasing the current density. Also, the crystallite size showed a significant increase with the increase of the current density, as shown in table (4).

Table (3): Crystal Structure Properties of the Coating Surface for Bath (1) Test Conditions

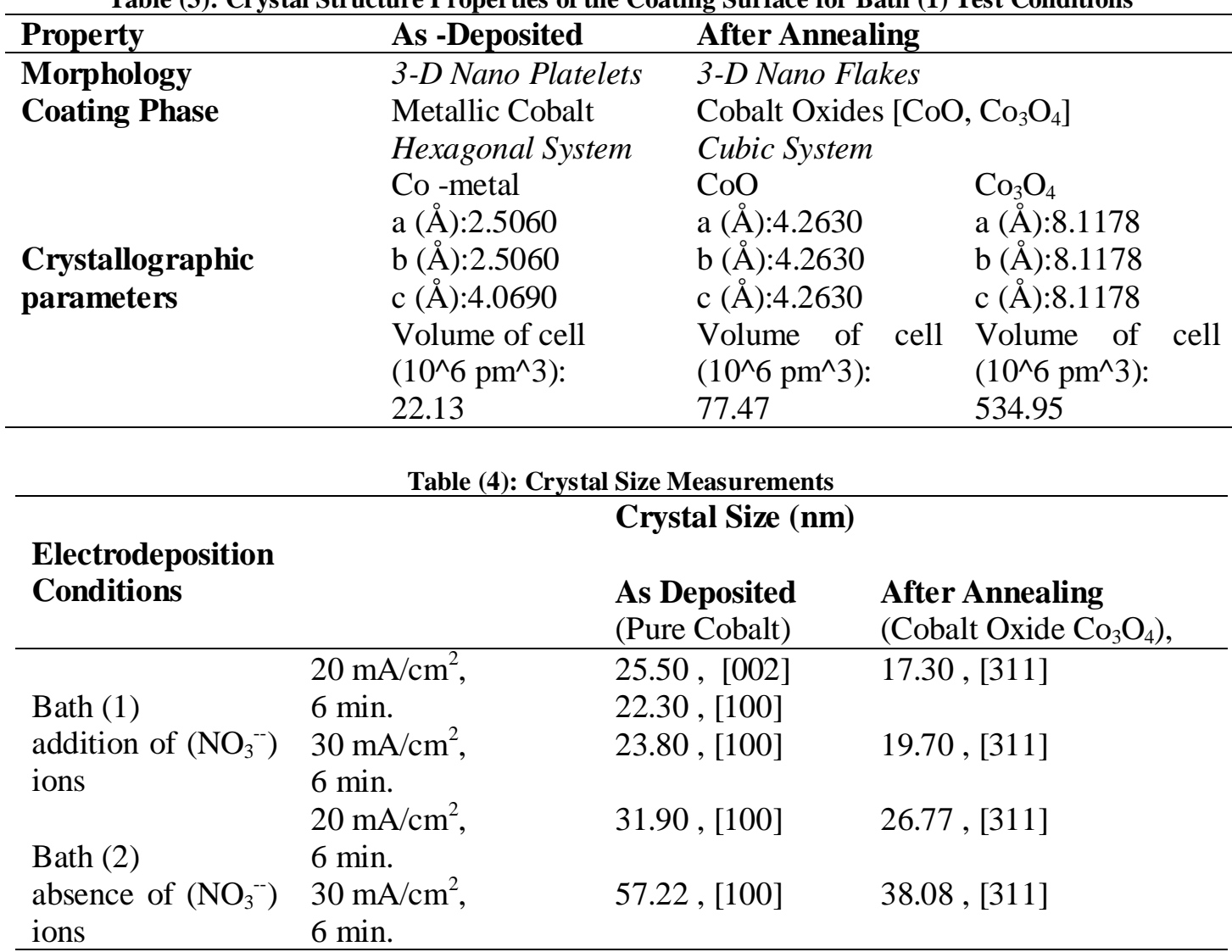

Scanning Electron Microscopy

Figures (7) and (8) show the scanning electron microscopy of a stainless steel 304 substrate covered with electrodeposited layer formed in bath-1 composition. Also, figures (9) and (10) show that when using bath-2 composition, the image (a) shows the electrodeposited pure cobalt surface layer, while image (b), shows cobalt oxide surface layer.
Figures (7-a) and (8-a) show the deposited film microstructure of pure cobalt at the as deposited conditions in bath-1 when applying current densities $\left(20\right.$ and $30 \mathrm{~mA} / \mathrm{cm}^{2}$ ) respectively. It can be seen that the deposited pure cobalt has compact and uniform surface morphology at micro scale revealing the uniformity of the deposition i.e. deposit formation and growth during whole time of deposition. It was noticed that, the internal nanostructure size slightly increased with increasing the current density. Higher 
magnification image clearly revealed that the deposited layers had lumpy and uneven surface all over the area, composed of interconnected plates which look like flakes. Also, it seems that most of flakes had vertical growth direction during deposition process on the cathode surface.

Figures (7-b) and (8-b) depicts the surface morphology of black cobalt oxide films after annealing treatment. It is obvious that the crystal structure of black cobalt oxide film shows a porous structure. The density and size of pores varies with different electrodeposition conditions. The crystal structure transformation from $\mathrm{HCP}$ system of the pure cobalt to FCC system of the cobalt oxide $\left(\mathrm{Co}_{3} \mathrm{O}_{4}\right)$, after the annealing treatment leads to thinning in the formed nano interconnected flakes, as mentioned in table (3). This form of morphology can provide a sample with large surface area and pores, which enable the prepared electro active material to exhibit better super thermal capacitive performance for use in solar absorption purposes.

The role of annealing treatment as a thermal oxidation process for the as deposited pure cobalt can be observed by monitoring the oxygen content change as reported in table (5).
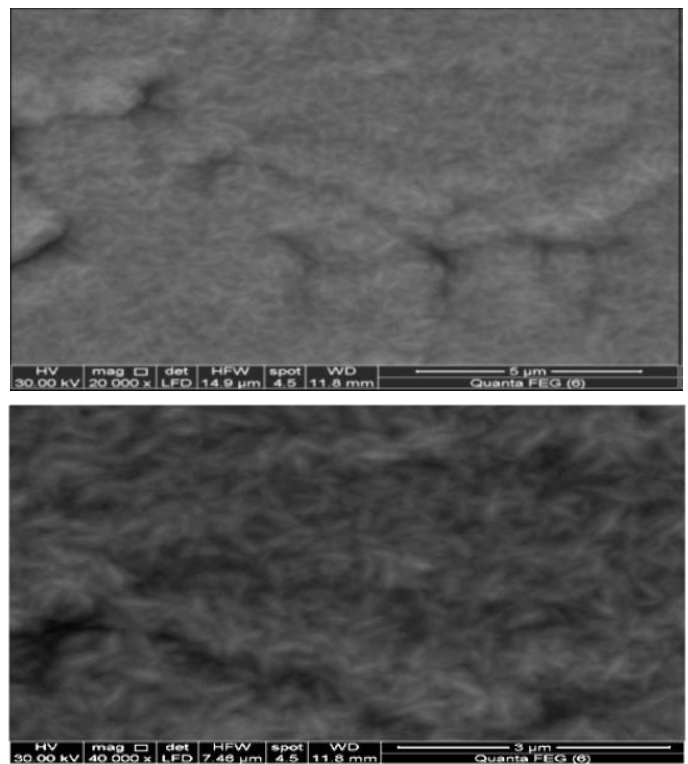

(a)
Figures (9-a) and (10-a) show the deposited film structure of pure cobalt deposited in bath-2 at current densities (20 and $30 \mathrm{~mA} / \mathrm{cm} 2$ ) respectively. It can be seen that the deposited pure cobalt had incompact and non-uniform surface morphology composed of interconnected unequal size platelets at micro scale revealing the non-uniformity of the deposition (i.e. deposit formation and growth during whole time of deposition). Meanwhile, the internal nanostructure size highly increased with increasing the current density. Higher magnification images clearly revealed that the deposited layers had lumpy and uneven surface at all areas. A different degree of crystallinity was observed (i.e. variation in size of formed inter crystalline structure

In figures (9-b) and (10-b), the surface morphology of black cobalt oxide films after annealing heat treatment shows a slightly porous structure. The size of formed pores is varying for different electrodeposition conditions. Even, the crystal structure morphology changes. It is seen from the figures that thinning occurred in the formed nano interconnected flakes, because of the crystal structure transformation from HCP system of the pure cobalt to FCC system of the cobalt oxide of both types $(\mathrm{CoO})$ and $(\mathrm{Co} 3 \mathrm{O} 4)$, after the annealing.
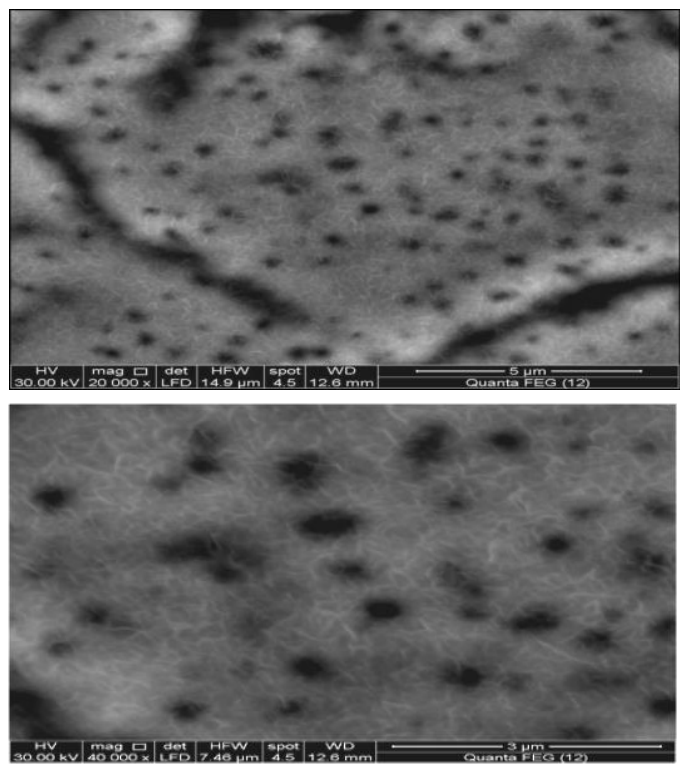

(b)

Figure (7): SEM of stainless-steel surface covered with; (a) cobalt metal as deposited, (b) cobalt oxides after annealing $\left(400^{\circ} \mathrm{C} / 10 \mathrm{~h}\right)$. Electrodeposition conditions; current density $\left(20 \mathrm{~mA} / \mathrm{cm}^{2}\right)$, deposition time $(6 \mathrm{~min}$. $)$ and bath -1 composition. 

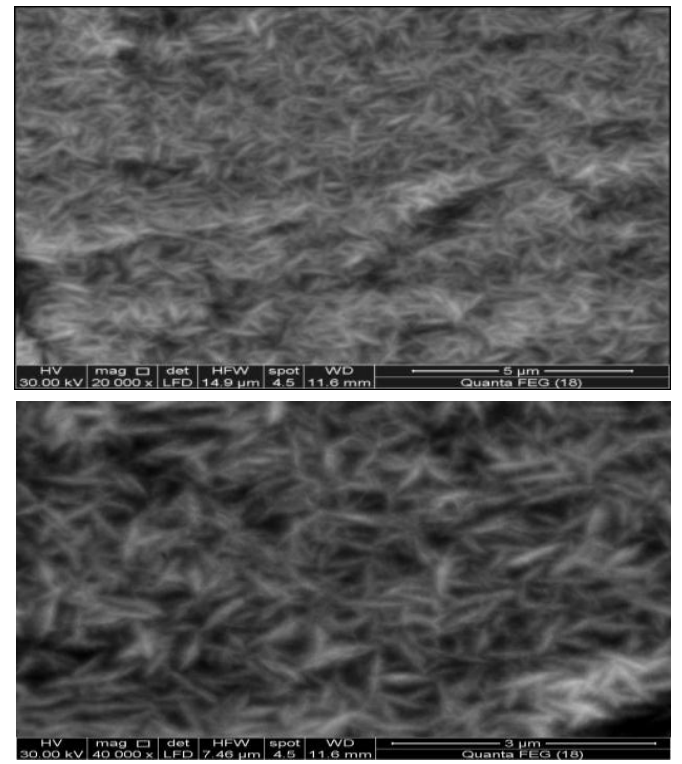

(a)
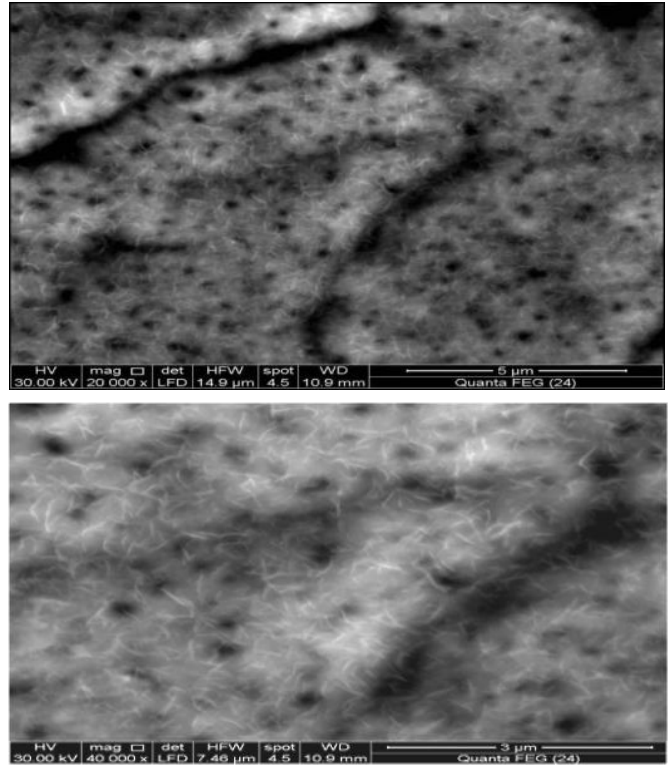

(b)

Figure (8): SEM of stainless steel surface covered with; (a) cobalt metal as deposited, (b) cobalt oxides after annealing $\left(400^{\circ} \mathrm{C} / 10 \mathrm{~h}\right)$. Electrodeposition conditions; current density $\left(30 \mathrm{~mA} / \mathrm{cm}^{2}\right)$, deposition time $(6 \mathrm{~min}$.), and bath -1 composition.
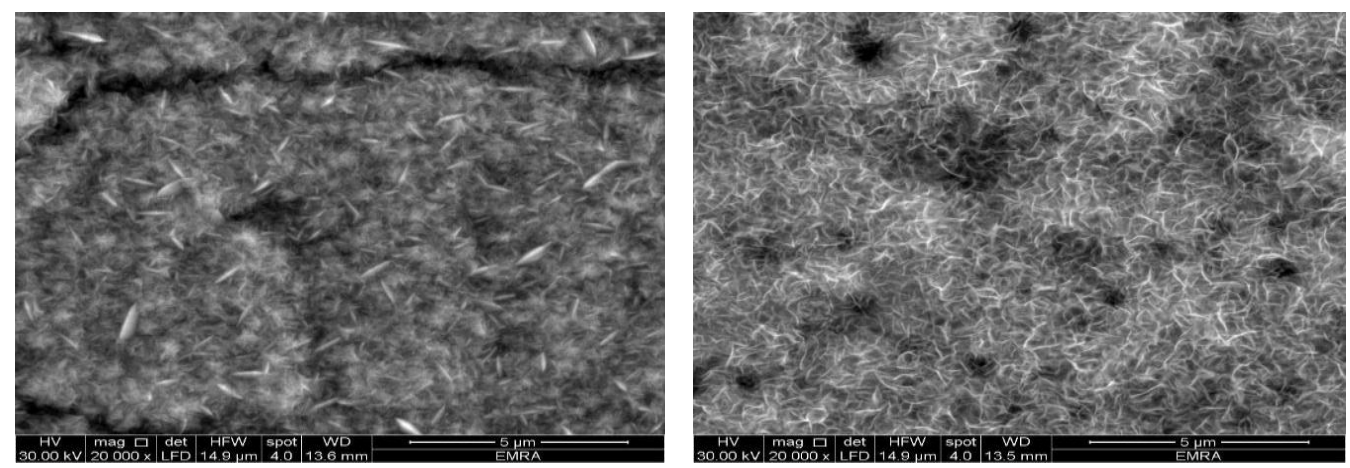

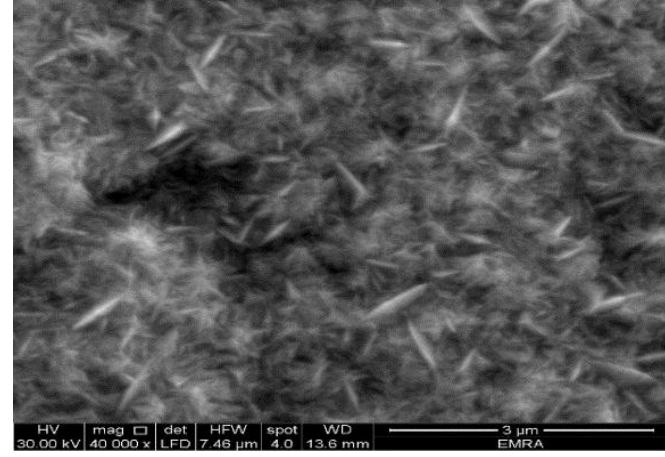

(a)

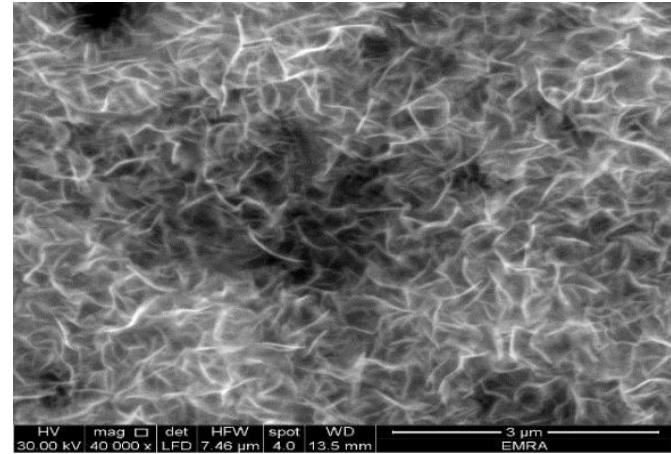

(b)

Figure (9): SEM of stainless steel surface covered with; (a) cobalt metal as deposited, (b) cobalt oxides after annealing $\left(400^{\circ} \mathrm{C} / 10 \mathrm{~h}\right)$. Electrodeposition conditions; current density $\left(20 \mathrm{~mA} / \mathrm{cm}^{2}\right)$, deposition time (6 min) and bath -2 composition. 

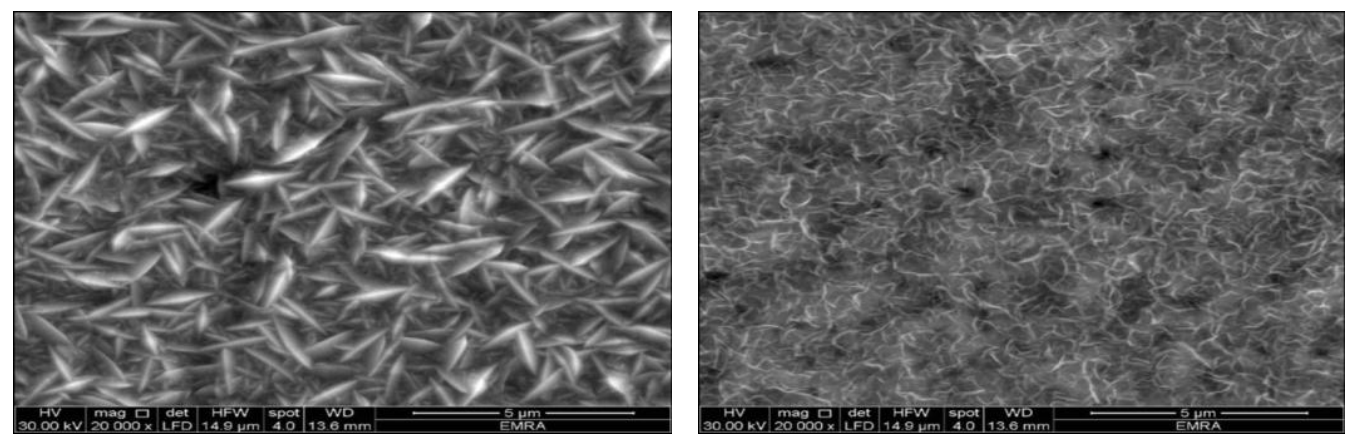

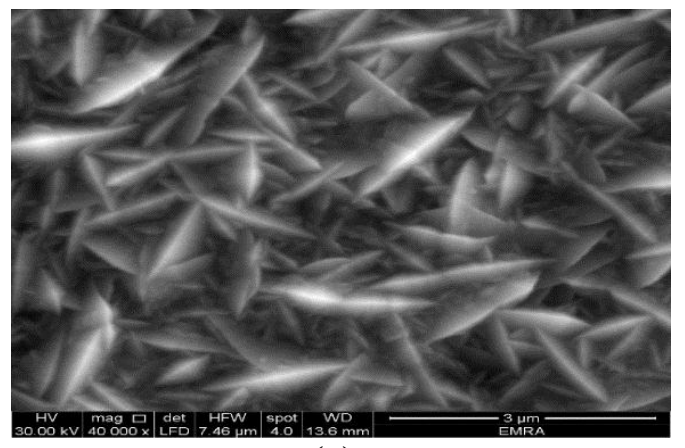

(a)

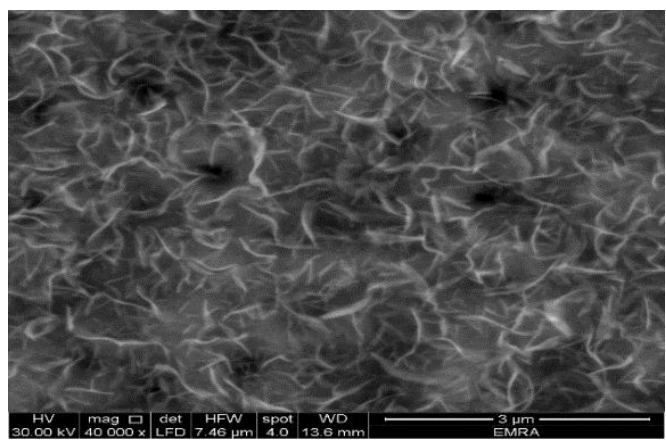

(b)

Figure (10): SEM of stainless steel surface covered with; (a) cobalt metal as deposited, (b) cobalt oxides after annealing $\left(400^{\circ} \mathrm{C} / 10 \mathrm{~h}\right)$. Electrodeposition conditions; current density $\left(30 \mathrm{~mA} / \mathrm{cm}^{2}\right)$, deposition time (6 min) and bath -2 composition.

Table (5): Effect of current density and annealing treatment on the surface layer composition. EDAX Analysis

\begin{tabular}{cccccc}
\hline \multirow{2}{*}{$\begin{array}{c}\text { Electrodeposition } \\
\text { Condition }\end{array}$} & \multicolumn{4}{c}{ Composition (at \%) } \\
\cline { 2 - 6 } & \multicolumn{2}{c}{ As Electrodeposited } & \multicolumn{2}{c}{ After Annealing } \\
\hline \multirow{2}{*}{ Bath-1 } & $20 \mathrm{~mA} / \mathrm{cm}^{2}$ & 83.60 & 5.22 & 60.24 & 20.85 \\
& $30 \mathrm{~mA} / \mathrm{cm}^{2}$ & 89.74 & 5.02 & 69.99 & 20.84 \\
\multirow{3}{*}{ Bath-2 } & $20 \mathrm{~mA} / \mathrm{cm}^{2}$ & 86.89 & 4.07 & 61.75 & 20.85 \\
& $30 \mathrm{~mA} / \mathrm{cm}^{2}$ & 91.22 & 4.10 & 67.88 & 29.39 \\
\hline
\end{tabular}

Roughness and Surface Topography

According to the roughness measurements presented in table (6), increase in the roughness values for all conditions was observed due to the oxidation process by annealing heat treatment. The greatest change was observed for the condition of use of bath-2 at current density $\left(20 \mathrm{~mA} / \mathrm{cm}^{2}\right)$ where, a decrease in roughness after electrodeposition was followed by increase after annealing heat treatment.

The 3D surface topography of the electrodeposited layer was obtained using a 3D Image Analyzing Software [SCANDIUM Software]. It is a facility in the SEM. Figures (11) and (12) give the topography of the surface layer deposited in bath-1 at current densities $20,30 \mathrm{~mA} / \mathrm{cm}^{2}$ respectively.
And, figures (13) and (14) show the topography of the surface layer deposited in bath-2. The images (a), show the electrodeposition surface of pure cobalt at as deposited conditions, while the images (b), presenting the layer surface of cobalt oxide after annealing thermal treatment.

The images (11-a) and (12-a) show the topography of surface as electrodeposited, where a slight increase in the size of the crystal structure with the increase in current density was observed. Meanwhile, images (11-b) and (12-b) show the surfaces topography after annealing heat treatment, where porous structure appears clearly with an obvious increase in the pores size with decreasing the current density. 
Table (6): Effect of electrodeposition parameters and annealing treatment on the roughness measurements

\begin{tabular}{lllll}
\hline \multirow{2}{*}{$\begin{array}{l}\text { Electrodeposition } \\
\text { Conditions }\end{array}$} & \multicolumn{4}{l}{ Roughness Measurements $(\boldsymbol{\mu m})$} \\
\cline { 2 - 5 } (Dep. Time 6 min.) & $\begin{array}{l}\text { Substrate } \\
\text { Stainless }\end{array}$ & $\begin{array}{l}\text { As } \\
\text { Steel } \\
\text { deposition } \\
\text { Pure Cobalt }\end{array}$ & Electro- & $\begin{array}{l}\text { After Annealing } \\
\text { Cobalt Oxide } \mathrm{Co}_{3} \mathrm{O}_{4}\end{array}$ \\
\hline Bath-1 & $20 \mathrm{~mA} / \mathrm{cm}^{2}$ & 0.09 & 0.11 & 0.16 \\
& $30 \mathrm{~mA} / \mathrm{cm}^{2}$ & 0.09 & 0.09 & 0.15 \\
Bath-2 & $20 \mathrm{~mA} / \mathrm{cm}^{2}$ & 0.09 & 0.07 & 0.32 \\
& $30 \mathrm{~mA} / \mathrm{cm}^{2}$ & 0.09 & 0.09 & 0.12 \\
\hline
\end{tabular}

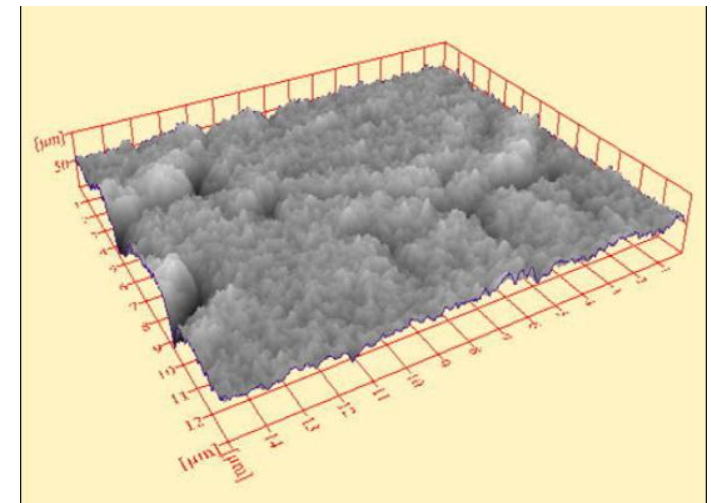

(a)

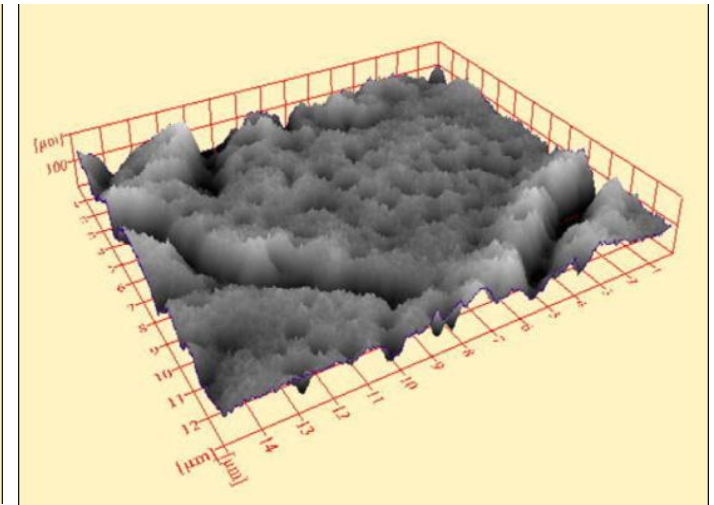

(b)

Figure (11): Surface topography of stainless steel surface covered with; (a) cobalt metal as deposited, (b) cobalt oxides after annealing $\left(400^{\circ} \mathrm{C} / 10 \mathrm{~h}\right)$. Electrodeposition conditions; current density $\left(20 \mathrm{~mA} / \mathrm{cm}^{2}\right)$, deposition time (6 min), and bath-1 composition.

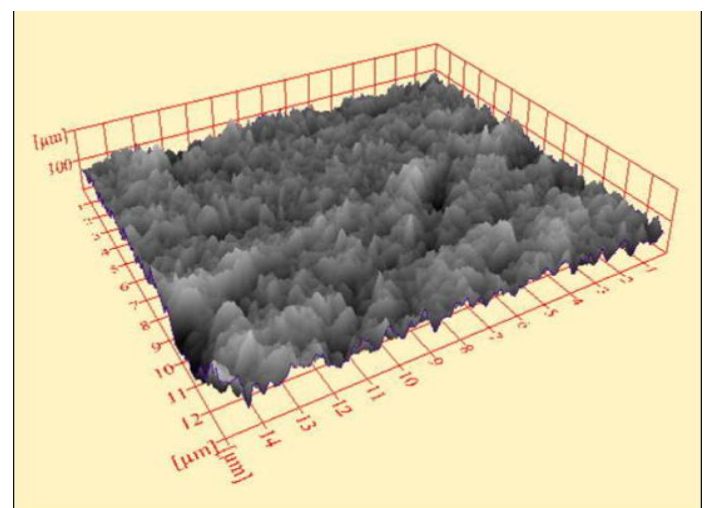

(a)

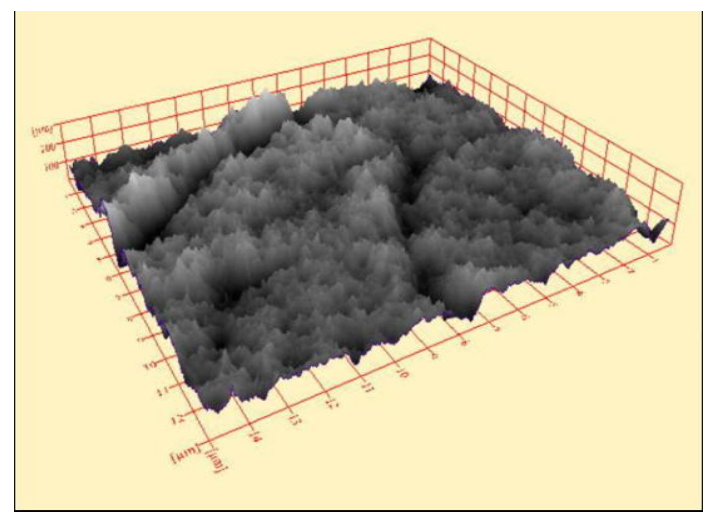

(b)

Figure (12): Surface topography of stainless steel surface covered with; (a) cobalt metal as deposited, (b) cobalt oxides after annealing $\left(400^{\circ} \mathrm{C} / 10 \mathrm{~h}\right)$.Electrodeposition conditions; current density $\left(30 \mathrm{~mA} / \mathrm{cm}^{2}\right)$, deposition time (6 min), and bath-1 composition.

The images (13-a) and (14-a) show the topography of surface as electrodeposited, where a massive increase in the size of the crystal with the increase in current density was observed. On the other hand images (13-b) and (14-b) presenting the surfaces topography after annealing, show that the two surfaces are nearly similar except for some uneven and lumpy appearance in the one deposited at 20 $\mathrm{mA} / \mathrm{cm}^{2}$. 


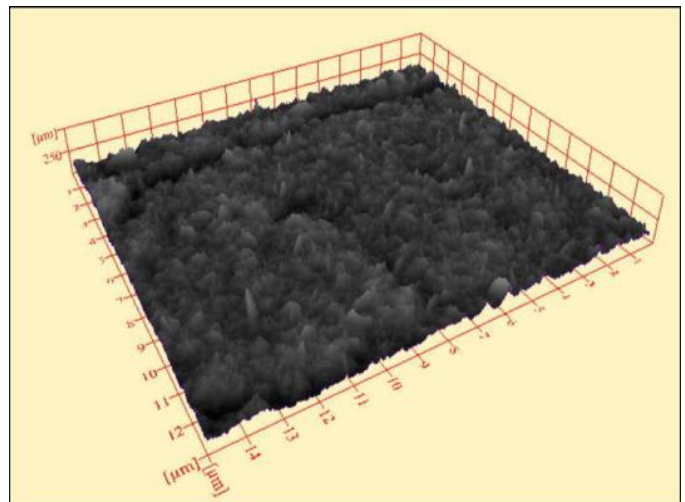

(a)

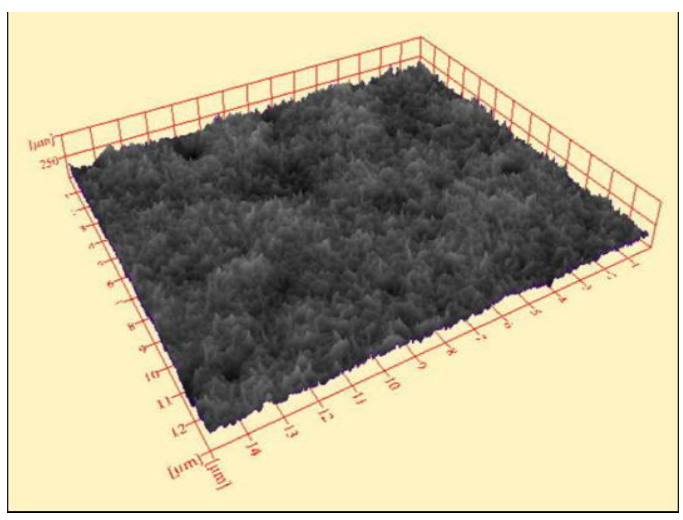

(b)

Figure (13): Surface topography of stainless steel surface covered with; (a) cobalt metal as deposited, (b) cobalt oxides after annealing. Electrodeposition conditions; current density $\left(20 \mathrm{~mA} / \mathrm{cm}^{2}\right)$, deposition time (6 $\mathrm{min})$ and bath-2 composition

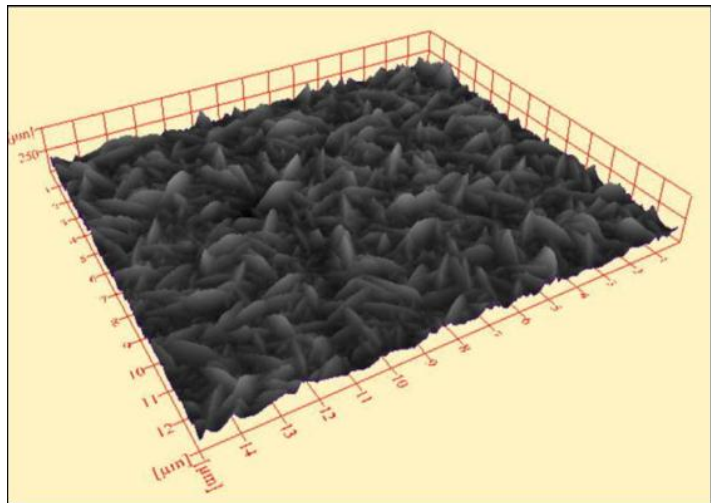

(a)

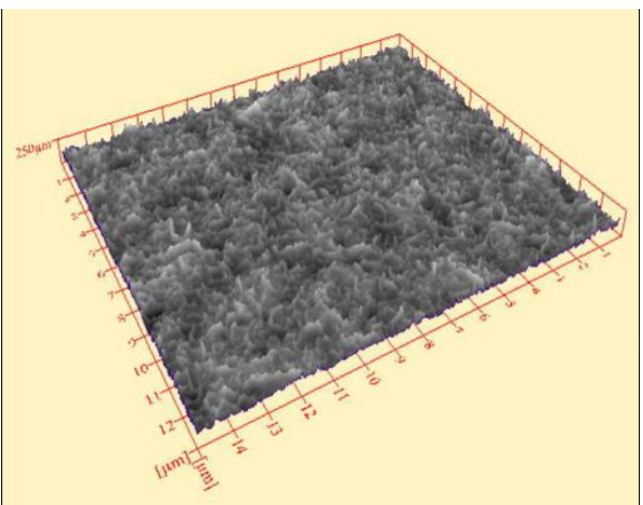

(b)

Figure (14): Surface topography of stainless steel surface covered with; (a) cobalt metal as deposited, (b) cobalt oxides after annealing $\left(400^{\circ} \mathrm{C} / 10 \mathrm{~h}\right)$.Electrodeposition conditions; current density (30 $\mathrm{mA} / \mathrm{cm}^{2}$ ), deposition time (6 min), and bath-2 composition.

\section{Optical Properties}

Absorption coefficient of the coating layers can be calculated according to Kirchhoff's law, which states that the sum of the absorptance, transmittance, and reflectance of the surface in particular wavelength equals to one. ${ }^{[3]}$

$\mathrm{A}+\mathrm{R}+\mathrm{T}=1$

Where $\mathrm{A}$ is absorptance, $\mathrm{T}$ is transmittance, and $\mathrm{R}$ is reflectance of surface. In the opaque surfaces where their transmittance is zero, it can be expressed as:

$$
\mathrm{A}+\mathrm{R}=1
$$

As shown in figure (15), and according to Plank's Equation, the energy of the incident spectrum is inversely proportional to its wavelength.

$E=h v=h\left(\frac{c}{\lambda}\right)$

Where; $\boldsymbol{E}$ is for energy (in Joules), $\boldsymbol{v}$ is for frequency [Hertz $\left.(\mathrm{Hz}), 1 \mathrm{~Hz}=1 \mathrm{~s}^{-1}\right], \boldsymbol{h}$ is Planck's constant $\left(6.626 \times 10^{-34} \mathrm{~J} . \mathrm{s}\right), \boldsymbol{c}$ is light velocity $\left(2.998 \times 10^{8} \mathrm{~m} / \mathrm{sec}\right]$ and $\lambda$ is wavelength $[\mathrm{nm}]$.

The optical properties were studied in the 300 $900 \mathrm{~nm}$ region which includes the visible light region $(380-750 \mathrm{~nm})$, near ultra violet region UV - $(<380 \mathrm{~nm})$, and near infra-red region - IR (> $750 \mathrm{~nm}$ ). The absorptance percentage $(\%)$ can be calculated from of the reflectance percentage (\%), which is measured by the UV-visible-near IR 
spectrophotometer used for optical properties investigation, as follows;

Absorptance $(\%)=100-$ Reflectance $(\%)$

Figure (16) presents the data calculated from equation (5) for the materials electrodeposited in bath- 1 and bath- 2 at applied current densities (20, $\left.30 \mathrm{~mA} / \mathrm{cm}^{2}\right)$ and optimum deposition time (6 min.). At current density $\left(20 \mathrm{~mA} / \mathrm{cm}^{2}\right)$ the coating layer formed in bath-1conditions had lower crystallite size $(17.3 \mathrm{~nm})$ and low roughness measurements $(160 \mathrm{~nm})$, the absorptance had the higher value near the ultra violet (UV) region about (98\%), which slightly decrease in the visible light region (95-98\%), then sharply decrease at the near infra-red region (IR). On the other hand, due to the increase in the roughness measurements $(320 \mathrm{~nm})$ and owning to greater crystallite size
$(26.77 \mathrm{~nm})$ for bath-2 conditions, the absorptance shows a normally stable behavior in the visible light region (about 97\%), which a slight decrease at both UV and IR regions.

According to Plank's concept, the selective coating layer at bath-1 condition can absorb the major part of sunlight spectrum which has the highest energy up to orange color zone with wavelength $600 \mathrm{~nm}$. On the other hand, the selective coating layer at bath-2 condition can absorb the minor part of sunlight spectrum which has the lowest energy near the infrared zone.

Thus, the solar absorptance efficiency of the selective coating layer formed by using bath-1 composition (addition of cobalt nitrate) is greater than that for layer formed by using bath-2 composition (absence of cobalt nitrate).

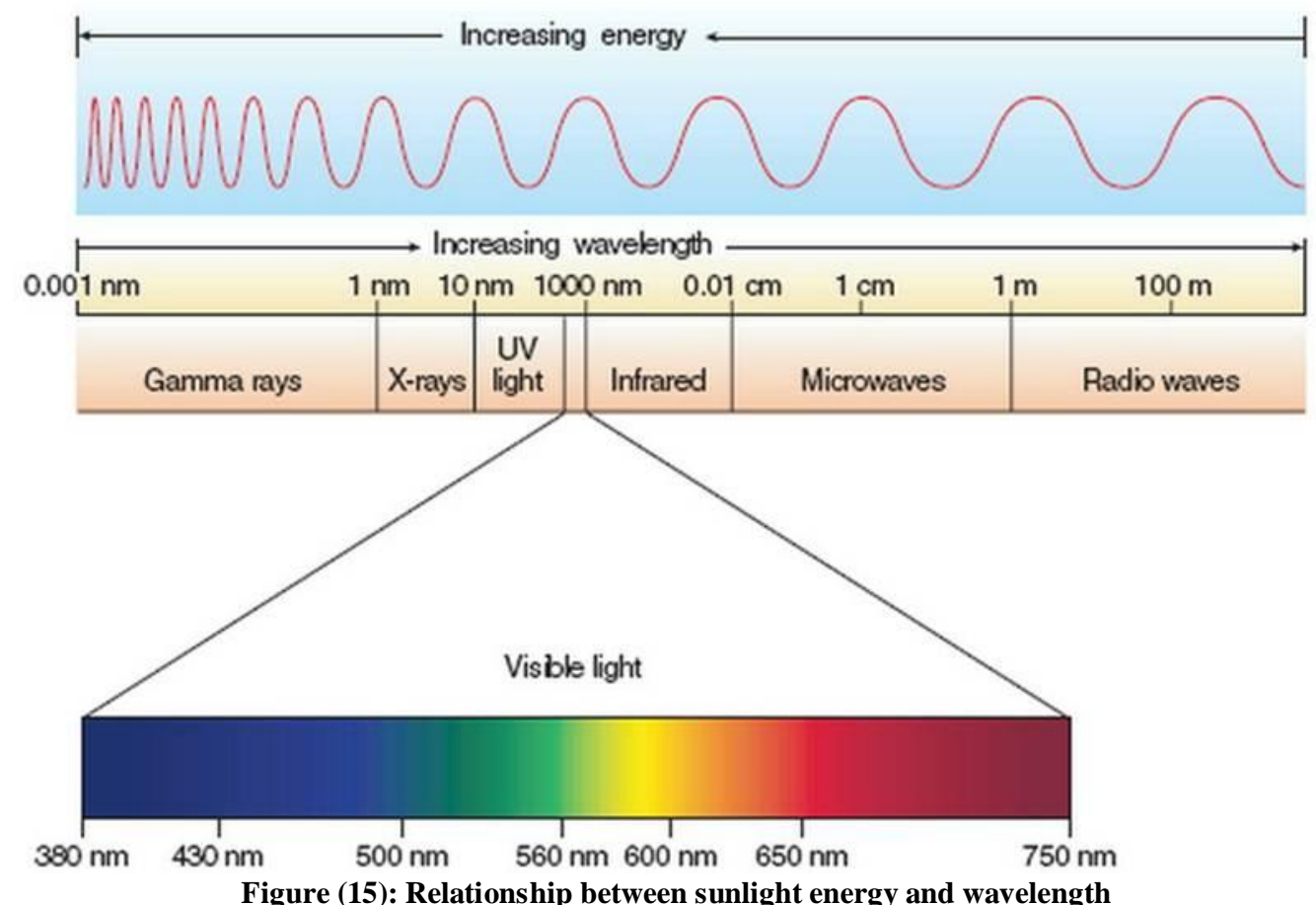




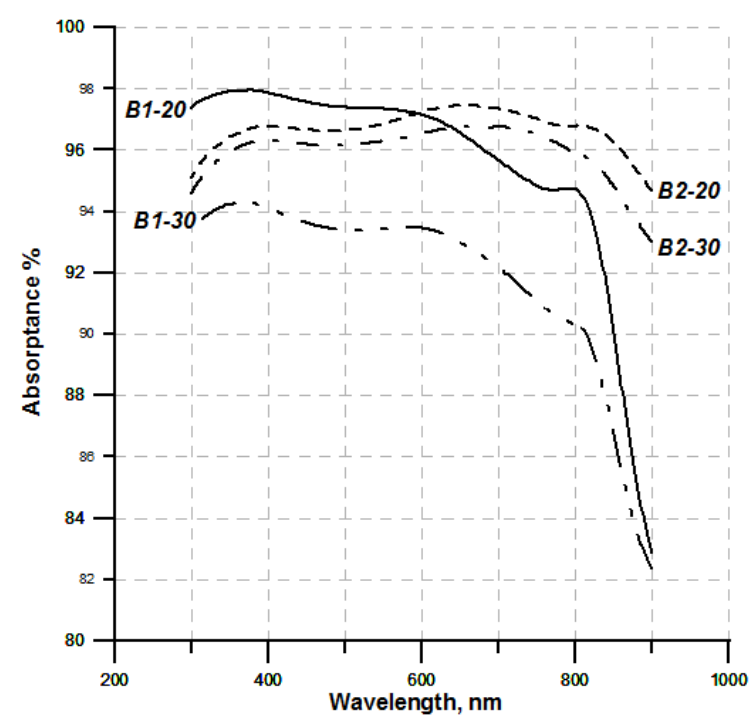

Figure (16): Effect of the current density and the composition of electrodeposition baths on the absorptance behavior of cobalt oxide layer

\section{Conclusions}

For the conditions applied in this study, the authors conclude the following;

1- The increase in the current density at fixed values of deposition time and electrolyte $\mathrm{pH}$, increase the degree of crystallinity and enlarge the crystallite size of the deposited pure cobalt, and vice versa.

2- The crystal structure transformation from HCP for pure cobalt to FCC for Cobalt oxides $\left(\mathrm{CoO}\right.$, and $\left.\mathrm{Co}_{3} \mathrm{O}_{4}\right)$ after annealing results a decrease in the crystallite size and morphology changes in the surface layer from interconnected nano platelets to interconnected nano flaks, this increases the roughness measurements and the topography changes.

3- There are obvious effects of the electrodeposition conditions and annealing heat treatment on the absorptance behavior of the selective formed layer on the stainless steel 304 substrate. The absorptance values about $98 \%$, for the high energy region of sunlight spectrum at bath condition of using cobalt nitrate, which is considered a high value as compared to the previous works.

\section{References}

1-K. D. Lee, Preparation and Characterization of Black Cobalt Solar Selective Coatings, Journal of the Korean Physical Society, Vol. 57, No. 1, July (2010) , pp. 111-119

2-M. Joly, Y. Antonetti, M. Python, M. Gonzalez, T. Gascou, J.Scartezzini, A. Schuler, Novel black selective coating for tubular solar absorbers based on a sol-gel method, Solar Energy 94 (2013) pp. 233239.

3-Z. Abdel Hamid, A. Abdel Aal and P. Schmuki, Nanostructured black cobalt coatings for solar absorbers, Surface and Interface Analysis.( 2008), 40, 1493-1499.

4-R. Hallaj , K. Akhtari, A. Salimi, S. Soltanian, Controlling of morphology and electrocatalytic properties of cobalt oxide nanostructures prepared by potentiodynamic deposition method, Applied Surface Science, 276, (2013), pp. 512-520.

5-A. Noorbakhsh, M. M. Mirkalaei, M. H. Yousefi, S. Manochehri, Electrodeposition of Cobalt Oxide Nanostructure on the Glassy Carbon Electrode for Electrocatalytic Determination of para-Nitrophenol, Electroanalysis (2014), 26, pp. 2716 - 2726

6-X. Yanpeng, A. Taleb, P. Jegoub, Electrodeposition of cobalt films with an oriented fir tree-like morphology with adjustable wetting properties using a self-assembled gold nanoparticle modified HOPG electrode, Journal of Materials Chemistry A, (2013), 1, pp. 11580-11588.

7-F. Pagnanelli, P. Altimari, M. Bellagamba, G. Granata, E. Moscardini, P. G. Schiavi, L. Toro, Pulsed Electrodeposition Of Cobalt Nanoparticles On Copper: Influence Of The Operating Parameters On 
Size Distribution And Morphology, Electrochimica Acta, 155, (2015), pp. 228-235.

8-J. R. Brownson, and C. Lévy-Clément, Electrodeposition of $\alpha$ - and $\beta$-cobalt hydroxide thin films via dilute nitrate solution reduction, physica status solidi (b) 245, No. 9, pp. 1785-1791 (2008)

9-P. G. Schiavi, P. Altimari, R. Zanoni, F. Pagnanelli, Morphology-controlled synthesis of cobalt nanostructures by facile electrodeposition: transition from hexagonal nanoplatelets to nanoflakes, Electrochimica Acta 220 (2016) pp. 405-416.

10-E. Barrera, M. P. Pardavé, N. Batina, and I. González, Formation Mechanisms and Characterization of Black and White Cobalt Electrodeposition onto Stainless Steel, Journal of The Electrochemical Society, 147 (5) 1787-1796 (2000).

11-I. KELPŠAITÉ ， J. BALTRUŠAITIS , E. VALATKA, Electrochemical Deposition of Porous Cobalt Oxide Films on AISI 304 Type Steel, MATERIALS SCIENCE (MEDŽIAGOTYRA). Vol. 17, No. 3. (2011), 236 - 243.

12-E. Barrera , I. Gonzals , T. Viveros , A new cobalt oxide electrodeposit bath for solar absorbers, Solar Energy Materials and Solar Cells 51 (1998) 69-82.

13-P. N. Shelke, S. D. Gunjal, P. S. More, K. C. Mohite, Y. B. Khollam, Optical Properties Of Co3o4 Films Deposited By Dc Electrochemical Method, Ijcps Vol. 4 Special Issue Etp - (2015), pp. 140-147

14-N. D. Ivanova, E. I. Boldyrev, S. V. Ivanov, and I. S. Makeeva, Electrochemical Synthesis of Black Cobalt, Russian Journal of Applied Chemistry, Vol. 76, No. 10, (2003), pp. 1589-1592.

15-L. M. Graham, The effect of boric acid on the growth mechanism of electrodeposited metal nanostructures, Doctor of Philosophy (2014). 